\title{
Publisher Correction: Revealing nitrogen-containing species in commercial catalysts used for ammonia electrosynthesis
}

Yifu Chen (D), Hengzhou Liu, Nguon Ha, Stuart Licht (D), Shuang Gu (D) and Wenzhen Li (D)

Correction to: Nature Catalysis https://doi.org/10.1038/s41929-020-00527-4, published online 26 October 2020.

In the version of this Analysis originally published, in Fig. 4 the second-from-bottom $y$-axis tick mark label was incorrect as $10^{-8}$; it should have been $10^{-10}$. This has now been corrected.

Published online: 22 February 2021

https://doi.org/10.1038/s41929-021-00588-z

(c) The Author(s), under exclusive licence to Springer Nature Limited 2021 